\title{
LA DIFÍCIL CONSTRUCCIÓN DE LA CIUDADANÍA PLURIÉTNICA: EL ZAPATISMO EN EL CONTEXTO LATINOAMERICANO ${ }^{1}$
}

\author{
Neil Harvey
}

Resumen: En las últimas dos décadas hemos visto el surgimiento y evolución en distintos paises latinoamericanos de movimientos indigenas que exigen reconocimiento y redistribución en el marco de los Estados nacionales de la región. En estos tiempos las diversas organizaciones indigenas han opuesto resistencia a la hegemonía neoliberal, mientras al mismo tiempo han planteado la posibilidad de construir sociedades más igualitarias y tolerantes que incluyan el apoyo a la ciudadania pluriétnica. Este artículo examina la experiencia de lucha de los rapatistas en México en un contexto comparativo latinoamericano.

Palabras clave: democracia, rapatismo, movimientos indigenas, América Latina, México, ciudadanía pluriétnica.

Enviado a dictamen: 18 de enero de 2007.

Aprobación: 08 de mayo de 2007.
Abstract: In the last two decades we have seen in various Latin American countries the emergence and evolution of indigenous movements that demand recognition and redistribution within the framework of the nation-states of the region. In these years, the different indigenous organizations have presented resistance to neoliberal hegemony, while at the same time they have put forward the possibility of building more equal and tolerant societies that includes support for multi-ethnic citizenship. This article examines the experience of the Zapatistas' struggle in Mexico within a comparative Latin American context.

Key words: democracy, zapatismo, indigenous movements, Latin America, Mexico, pluriethnic citizenship.

Introducción

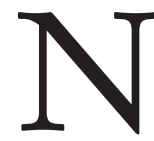
o cabe duda de que el 2006 fue un mal año para la democracia y los derechos ciudadanos en México. Entre los hechos más importantes destacan los actos de represión policiaca en San Salvador Atenco y Oaxaca, los controvertidos comicios presidenciales y los conflictos post-electorales. Al finalizar el año, México enfrentaba una crisis profunda en la cual las instituciones quedaban cuestionadas y se vivía una creciente polarización política. Ante este escenario, la investigación de los procesos que afectan los derechos democráticos, sobre 
todo de los grupos más marginados, se ha vuelto una necesidad urgente.

Este artículo se centra en la difícil construcción de la ciudadanía pluriétnica, un concepto que se refiere al reconocimiento que se da a los derechos específicos de los pueblos indígenas dentro de un marco nacional. En varios países latinoamericanos $\mathrm{y}$ del mundo, hemos visto en los últimos veinte años diversos intentos de incluir las demandas de los pueblos indígenas en la reforma de las constituciones nacionales. En algunos países, como México por ejemplo, este proceso se da en el contexto de procesos de paz entre movimientos armados y gobiernos, mientras en otros, las demandas indígenas han encontrado expresión en asambleas constituyentes convocadas para superar situaciones de ingobernabilidad. Cabe señalar que, a pesar de sus diferencias nacionales, los movimientos sociales comparten el mismo discurso democrático, fincado en el derecho internacional, que ha buscado lograr que la categoría de ciudadanía sea incluyente de todos los grupos étnicos, como los indígenas y los afrodescendientes. Con ello, la ciudadanía diferenciada (Young, 1998) rompió con la homogeneización cultural que caracterizaba las constituciones modernas de sesgo eurocéntrico, aunque, para algunos, los derechos diferenciados representaran una amenaza a la unidad nacional. En este artículo, examino los obstáculos que han impedido el reconocimiento de la ciudadanía pluriétnica en México y las consecuencias de esta respuesta negativa para el zapatismo como movimiento social.

\section{Ciudadanía y zapatismo}

Una de las formulaciones de la ciudadanía más influyente es la de T.H. Marshall ([1949]1998). Basándose en un análisis histórico de la ciudadanía en Gran Bretaña, Marshall describió tres tipos de derechos: cívicos, políticos, y sociales. Argumentó que los derechos cívicos (como el derecho a la protección contra la tortura, la detención arbitraria, y la igualdad ante la ley) fueron establecidos en Inglaterra en el siglo XVIII. Este tipo de derecho fue ampliado con la conquista de los derechos políticos en el siglo XIX, lo cual permitió la extensión del sufragio a la población masculina adulta. En el siglo XX la introducción de los derechos sociales (a la educación, la salud y el seguro social) completaron el cuadro de la ciudadanía plena y ganó un cierto grado de consenso entre los principales partidos políticos hasta el auge del neoliberalismo en los ochenta.

$\mathrm{El}$ acceso a estos derechos nunca fue tan sencillo, y, en el concepto de Marshall, hay una marcada tendencia hacia la homogeneización social que no toma en cuenta las diferencias de género y de cultura. Por lo tanto, como señalan Fraser y Gordon (1994), la ciudadanía implícitamente privilegiaba al hombre blanco como el principal actor público, tanto en lo económico como en lo político, lo cual se basaba en la subordinación de las mujeres y de los grupos minoritarios. No obstante, la atención sobre el concepto de ciudadanía, en las democracias modernas, se mantuvo gracias en parte a los mismos movimientos sociales que demandaban el reconocimiento de sus derechos civiles, políticos y sociales.

En el campo de la teoría política, Kymlicka (2002) ha descrito el auge del concepto de ciudadanía, desde los ochenta, en los Estados Unidos, Canadá y Europa. Argumenta que este renovado interés se debe a diversos problemas y presiones, sobre todo, el abstencionismo electoral y la apatía política, las transformaciones demográficas producidas por nuevos flujos migratorios y las demandas de poblaciones minoritarias por el reconocimiento 
de sus lenguas y culturas en el sistema educativo. El tema de la ciudadanía, aunque muy antiguo en la filosofía política, ha cobrado cada vez mayor importancia debido a estos cambios y a su impacto en la diversificación social y la movilidad transfronteriza.

En México, la ciudadanía se volvió un tema importante durante los noventa debido a su relación con la transformación política en el país. Para entender las posibilidades de la democratización, se hizo necesario investigar los cambios en la cultura política y las formas de participacion pública (Durand Ponte, 2003). A diferencia de la conceptualización de Marshall, los derechos cívicos no eran garantizados y los derechos políticos eran nuevos y, muchas veces, difíciles de liberar del legado del autoritarismo. Por su parte, los derechos sociales habían sido manipulados por el clientelismo para afianzar el control político ejercido por el Estado y el Partido Revolucionario Institucional (PRI). Al mismo tiempo, la implementación del modelo neoliberal atentaba contra aquellos derechos sociales que habían sido conquistados. Es en este contexto que la demanda de derechos indígenas se insertó como un elemento esencial en la democratización de un país pluriétnico (De la Peña, 1999). La rebelión zapatista ocurrió en un momento cuando muchas organizaciones civiles estaban ya presionando para defender y ampliar los derechos cívicos, políticos, sociales y culturales. En cierta forma, los zapatistas, con su discurso amplio a favor de la democracia, la justicia y la paz, reivindicaban todas estas demandas, todas estas categorías de derechos ciudadanos, y no solamente en México.

El zapatismo ha participado en un doble movimiento: por un lado, ha tratado de producir cambios duraderos en el sistema político, pero, por el otro, ha buscado construir sus propios espacios de autogobierno local y regional. Como muchos analistas han observado, en América Latina los indígenas no exigen la separación y la independencia, sino la participación igualitaria en la toma de decisiones que les afectan a ellos y al resto de la ciudadanía (González Casanova y Roitman, eds. 1996 ; Díaz Polanco, 2004 ; López Bárcenas, 2002 ; Stavenhagen, 1996). En este sentido, no hay que olvidar la histórica marginación de los pueblos indígenas en la construcción de los Estados modernos. Las democracias latinoamericanas presentan una ambiguedad central: si por un lado permiten pensar en una apertura hacia la diversidad cultural y política, por el otro, cargan con un legado de conceptos y estructuras etnocentristas. Por lo tanto, el zapatismo ha buscado incidir en la transformación del Estado mexicano, sobre todo a través de los Acuerdos de San Andrés, para que la democratización en México no termine en un nuevo sistema excluyente. Es decir, el objetivo político del zapatismo es la construcción de una ciudadanía pluriétnica y es en este contexto que la autonomía indígena puede contribuir a la reforma democrática del Estado, la cual, como veremos, sigue siendo una tarea pendiente. $\mathrm{Al}$ mismo tiempo, el zapatismo contibuye a esta tarea en su trabajo de base, creando nuevos espacios de participación, como las juntas de buen gobierno, que fueron establecidas en 2003 (Revista Memoria, 2003 ; Múñoz Ramírez, 2003: 242-253). Son estos espacios en consolidación y sus alianzas con otros sectores populares los que demuestran el mayor impacto del zapatismo, y no tanto la transformación del marco legal e institucional, el cual sigue siendo gobernado por el proyecto neoliberal. En lo que sigue intentaré explicar este impacto a través de una comparación del zapatismo con las experiencias de otras luchas indígenas en America Latina. 


\section{Modernización excluyente y luchas indígenas}

A diferencia de las teorías dominantes de la modernización en América Latina, los pueblos indígenas no han desaparecido, aunque sí se han transformado a través de su cada vez mayor relación con las instituciones económicas, políticas y culturales de los estados nacionales. Hoy en día existen alrededor de ochocientos grupos etnolinguísticos en América Latina. Los más grandes se encuentran en las mismas regiones en las que florecieron las civilizaciones prehispánicas: los quechuas y aymaras en la parte central de los Andes, los nahuas en la meseta central de Mexico y los mayas en el sur de México, Guatemala, Belice, Honduras y El Salvador. ${ }^{2}$

En contraste con las zonas altas de México, Guatemala y los Andes, en las tierras bajas de la cuenca amazónica y las selvas centroamericanas la población indígena es mucho menor, pero se caracteriza por su gran diversidad etnolinguística. Los indígenas que viven en las zonas altas han tenido más contacto con las sociedades dominantes $\mathrm{y}$, con ello, han experimentado un mayor nivel de incorporación a las estructuras políticas de los estados nacionales, mientras la población indígena de las tierras bajas vivía hasta tiempos recientes en zonas de difícil acceso, lo cual limitó el alcance de los gobiernos centrales. Este aislamiento fue roto en la segunda mitad del siglo XX por la expansión de la frontera agrícola y ganadera, y por la implementación de proyectos de desarrollo nacionales y transnacionales.

No obstante, los pueblos indígenas en América Latina comparten algunas similitudes en cuanto a su relación con la tierra y el territorio. Su supervivencia ha dependido del acceso continuo a tierras comunales y al mantenimiento de equilibrios ecológicos. Sin embargo, las incursiones de las corporaciones paraestatales y privadas y el mercado global han amenazado su seguridad respecto a la tenencia de la tierra y en muchos casos han derivado en el deterioro del medio ambiente. Ejemplos ilustrativos de estos cambios son los efectos de la construcción de presas hidroeléctricas, la contaminación de tierras y acuíferos debido a la explotación petrolera y minera, la destrucción de bosques y selvas debido a la tala inmoderada y la colonización desenfrenada.

Por estas razones, la protección de los derechos a la tierra se convirtió en una demanda central de los movimientos indígenas a lo largo del continente y, en la actualidad, permite la promoción no sólo de los derechos indígenas, sino también de formas de producción socialmente justas y sustentables.

La lucha por la protección de los derechos a la tierra empezó a cobrar mayor importancia en los países sudamericanos a principios de la década de los sesenta. La primera respuesta organizada vino de los indígenas shuar de la zona amazónica ecuatoriana. Con el apoyo de misioneros salesianos, los shuar organizaron comités locales y una confederación shuar en 1964. Se mobilizaron para exigir el reconocimiento de sus territorios tradicionales y construyeron coaliciones regionales con otros grupos de la cuenca amazónica, quienes, en los setenta, tuvieron que enfrentar presiones similares. En 1980, estos grupos se unieron en la Confederación de Nacionalidades Indígenas de la Amazonia Ecuatoriana (CONFENIAE) para oponerse a las actividades de empresas petroleras y madereras y a los efectos negativos de una colonización mal planeada. En el mismo año se unió la CONFENAIE con indígenas de la sierra ecuatoriana y ayudó en la creación de la Confederación de Nacionalidades Indígenas del 
Ecuador (CONAIE). Durante los próximos diez años, tanto el movimiento amazónico como el de la sierra maduraron y ganaron presencia en el escenario nacional, tanto que culminaron en un levantamiento popular, en 1990, y en una marcha de la amazonia a Quito, en 1991, la cual ganó la titulación de más de mil hectáreas de tierras indígenas. Un levantamiento similar, en 1994, obligó al gobierno a ceder en sus planes de privatizar la tenencia de la tierra.

En Bolivia se dio un proceso similar a partir de los setenta, aunque las organizaciones indígenas de las tierras altas eran menos independientes que en el Ecuador. Esto se debía a su incorporación en una confederación laboral que dominaba tanto el discurso político como el contenido de las demandas sociales. Sin embargo, la imposición del modelo neoliberal en los ochenta fue acompañada de un debilitamiento del movimiento obrero, y, por consecuencia, de las organizaciones indígenas afiliadas. Al igual que en el Ecuador, los movimientos más independientes fueron los de los indígenas de la zona amazónica boliviana que luchaban en contra de las incursiones de las empresas madereras. Fue esta lucha la que llevó a una exitosa 'Marcha por el Territorio y la Dignidad', en 1990, la que dio como resultado la titulación de más de dos millones de hectáreas para los pueblos indígenas (Van Cott, 2001). El gobierno boliviano también aprobó una nueva ley agraria, en 1996, aceptó el concepto de derechos territoriales. Para 1997, el gobierno había reconocido siete territorios indígenas con un área total de 2.6 millones de hectáreas (Yashar, 1999: 94).

En el caso de Colombia, el primer movimiento indígena de esta época nació en el Valle del Cauca a principios de los sesenta. Este movimiento buscó la recuperación de tierras ancestrales.
En la siguiente década se desarrollaron dos vertientes, una que enfatizaba la demanda agraria (por ejemplo, en la Organización Nacional de Indígenas de Colombia, ONIC) y otra que se enfocaba más en el fortalecimiento de las estructuras de gobierno indígena (Autoridades Indígenas del Suroeste, AISO). A pesar de ser una población relativamente pequeña, como veremos más adelante, los indígenas en Colombia han logrado tener un impacto político significativo en la legislación nacional. Al igual que en el Ecuador, ambas vertientes del movimiento han considerado la reforma agraria no solamente como un objetivo material, sino también como la base sobre la cual se pueda reconstituir y defender las culturas indígenas. Como tal, ofrecen alternativas concretas para la creación de un mundo distinto y nuevo.

En México, la lucha por la tierra se intensificó en los setenta cuando el gobierno populista prometió revivir su programa de reparto agrario. Sin embargo, para finales de la década, esta promesa no había sido cumplida y la política oficial empezó a dar mayor peso a la productividad y fomentó las inversiones en el campo. Durante los ochenta, se celebraron en México varios foros, marchas y protestas para exigir la continuación del reparto agrario, una demanda que fue particularmente importante en las zonas indígenas del estado de Chiapas. La negativa del gobierno frente a esta demanda (expresada claramente en la reforma salinista al Artículo 27 constitucional, en 1991) fue uno de los factores que llevó a los zapatistas a tomar la decisión de levantarse en armas en 1994 (Harvey, 2000). De manera parecida a los movimientos indígenas en el Ecuador, Bolivia y Colombia, los zapatistas han combinado sus demandas agrarias con las de corte cultural y político. Estas demandas fueron plasmadas en los 
Acuerdos de San Andrés sobre los Derechos y Cultura Indígenas, los cuales fueron firmados por los representantes zapatistas y gubernamentales en febrero de 1996 (Hernández Navarro y Vera Herrera, 1998).

Finalmente, en Guatemala, vemos también la importancia de la lucha agraria para defender y reconstruir las instituciones culturales y políticas de los pueblos indígenas. Los primeros intentos de reforma agraria fueron revertidos por el golpe militar de 1954. En las siguientes décadas los canales de participación política y económica fueron fuertemente controlados por los grupos dominantes. Los movimientos guerrilleros pugnaban por el cambio revolucionario y, a principios de los ochenta, lograron ganar mayor presencia entre la población rural e indígena. Con el argumento de que las comunidades indígenas formaban una base social de apoyo a la guerrilla, el gobierno emprendió una ofensiva militar que culminó en la masacre de miles de indígenas y la destrucción de sus comunidades. Una vez consumada esta represión genocida, los militares permitieron la elección de un gobierno civil, aunque siguen manteniendo el control en la toma de decisiones en cuanto a la política interior. Para finales de los ochenta, este modelo de 'democracia restringida' fue fuertemene impugnado por los movimientos sociales, sobre todo los de los pueblos indígenas que exigían justicia por las violaciones sufridas. Al mismo tiempo, los gobiernos civiles tuvieron un acercamiento con los grupos guerrilleros para iniciar negociaciones con el objetivo de poner fin al conflicto armado. En este contexto, los representantes indígenas lograron incidir en las negociaciones de paz, lo cual fue reflejado en un conjunto de acuerdos sobre el reconocimiento de los derechos de los pueblos indígenas. Sin embargo, dichos acuerdos fueron rechazados en un referéndum realizado en 1999, en el cual solamente votó el $18 \%$ de los empadronados. Este resultado se debió en gran parte a la propaganda de los sectores derechistas que argumentaron que los acuerdos llevarían a la ruptura de la nación.

Con lo arriba mencionado se desprende que la construcción de la ciudadanía pluriétnica depende de los siguientes principios: (i) el reconocimiento constitucional de los derechos colectivos de los pueblos indígenas; (ii) el reconocimiento del derecho de autodeterminación de los pueblos indígenas a través de sus propias formas de gobierno e impartición de la justicia; (iii) el reconocimiento de derechos territoriales de los pueblos indígenas para que éstos puedan participar como iguales en el diseño e implementación de proyectos de desarrollo y conservación de sus tierras y recursos naturales; (iv) el reconocimiento del derecho a la promoción de las lenguas y culturas indígenas en la educación y en los medios de difusión. Es importante señalar que el reconocimiento de estos derechos debe de ir acompañado por una política de redistribución de los recursos y de la tierra para permitir el pleno ejercicio de los derechos indígenas. Con estos principios, se plantea la reforma de los estados nacionales para superar la exclusión, la discriminación y la asimilación forzada. Se abre la posibilidad de repensar la nación en toda su diversidad, con mayores espacios de participación y respetando las diferencias en un nuevo pacto social (Díaz Polanco y Sánchez, 2002). Este conjunto de principios se encuentra plasmado en el Convenio 169 de la Organización Internacional de Trabajo (OIT) de 1989, pero su aplicación depende de las particularidades institucionales y políticas de cada nación. Una comparación de las experiencias latinoamericanas recientes en este campo nos 
lleva a analizar dos procesos diferentes, aunque en ocasiones mezclados: (i) las negociaciones entre gobiernos y movimientos armados; y (ii) la reforma del marco constitucional.

\section{Procesos de paz y derechos indígenas}

El zapatismo es una de las pocas expresiones de un movimiento armado dirigido por comandantes indígenas, lo cual nos obliga a compararlo en dos ámbitos, el de las negociaciones de paz y el de la reforma constitucional. En el primer ámbito, es importante explicar las razones por las cuales el proceso de paz en Chiapas no ha logrado soluciones a los problemas que suscitaron la rebelión armada. Para ello, hay que tomar en cuenta por lo menos dos variables: (i) los incentivos para que los gobiernos acepten negociar reformas políticas con movimientos armados; y (ii) la relación entre las pláticas de paz y el proceso más amplio de democratización en el cual inciden otros actores nacionales.

Un análisis comparativo de los procesos de paz en Colombia, El Salvador, Guatemala y México revela que la primera variable depende de las diversas presiones ejercidas por las elites nacionales, la comunidad internacional y las organizaciones de la sociedad civil. En Colombia, en los años ochenta, la capacidad militar de los movimientos guerrilleros fue tanta que algunos sectores de las elites económicas y políticas empezaron a ver la necesidad de negociar una salida política a la crisis nacional. En este contexto se pudo lograr el desarme de algunos de los grupos guerrilleros, y su incorporación a la vida política a través de una asamblea constituyente, y la elaboración de una nueva Constitución política. En El Salvador, el empate militar entre el Frente Farabundo Martí de Liberación Nacional (FMLN) y el ejército salvadoreño llevó igualmente a algunos sectores de la elite a plantear la necesidad de negociar con la guerrilla. Su decisión también respondió a la reducción de la ayuda militar estadounidense en el nuevo contexto del fin de la guerra fría y el repudio internacional provocado por los asesinatos de sacerdotes jesuitas a finales de 1989. En Guatemala, donde la fuerza guerrillera era menor, las negociaciones tardaron más, pero fueron alentadas tanto por los movimientos sociales a través de la Asamblea de la Sociedad Civil (ASC) y el papel importante de la Organización de las Naciones Unidas (ONU). En México, sin embargo, las elites económicas no han sentido la necesidad de presionar al gobierno para que éste negocie con los zapatistas. Cuando el zapatismo tuvo un impacto más directo en la profundización de una crisis de confianza de inversionistas, a finales de 1994, la estabilidad financiera fue restablecida por el apoyo del gobierno de los Estados Unidos y una ofensiva militar más enérgica en contra de las comunidades rebeldes en febrero de 1995.

En estas condiciones, las presiones para que el gobierno mexicano se sentara a negociar con el EZLN no venían ni de las elites ni de actores internacionales, sino de la sociedad civil nacional e internacional. Sin embargo, esta presión no logró influir en la otra variable necesaria para alcanzar una solución política al conflicto, es decir, la ubicación del proceso de paz como crucial para la democratización nacional. En México, el gobierno buscó evitar que los diálogos de San Andrés incidieran en un proceso de cambio político controlado desde el ejecutivo y las dirigencias de los principales partidos políticos. De esta manera podemos entender el poco interés de los representantes gubernamentales en la implementación de los acuerdos sobre los 
derechos y cultura indígenas (firmados en febrero de 1996) como en la negociación de la reforma del Estado (la segunda mesa de diálogo, programada para junio de 1996). Para las elites políticas, el zapatismo era una expresión local del 'problema indígena', pero jamás un elemento central en el diseño de una reforma política nacional. Ésta fue monopolizada por el poder ejecutivo y los partidos políticos y, aunque condujo a reformas electorales necesarias, deja muchas tareas que siguen siendo pendientes hasta la fecha, y destaca aquí la creación del marco constitucional necesario para reconocer una ciudadanía pluriétnica.

Después de la firma de los Acuerdos de San Andrés, el gobierno de Ernesto Zedillo (19942000) se negó a implementarlos, argumentando que su contenido era una amenaza potencial a la unidad nacional. Los zapatistas suspendieron el diálogo con el gobierno y, en un intento de salvar las negociaciones, a finales de 1996, el organismo legislativo denominado Comisión para la Paz y la Reconciliación en Chiapas (COCOPA) redactó una nueva versión de los Acuerdos, la cual ganó la aprobación de los zapatistas pero no la del gobierno de Zedillo.

La derrota del PRI en las elecciones presidenciales en 2000 creó la esperanza de que el nuevo presidente, Vicente Fox, del Partido de Acción Nacional (PAN), iba a lograr el apoyo del Congreso para aprobar la iniciativa de ley de la COCOPA. Al mismo tiempo, los zapatistas emprendieron una marcha desde Chiapas hasta la Ciudad de México, la llamada Marcha del Color de la Tierra, para exigir su aprobación. Sin embargo, la comisión del Senado encargada de aprobar la legislación, con el apoyo de los representantes de todos los partidos políticos, modificó la iniciativa para limitar el alcance de la autonomía. Específicamente, la nueva legislación no reconoce a los pueblos indígenas como sujetos de derecho y se mantiene una relación basada en el paternalismo que deja en manos del gobierno la provisión de servicios y programas asistenciales (Harvey, 2004; Hernández Sierra y Paz, 2004; Higgins, 2001).

Los zapatistas rechazaron estas modificaciones y suspendieron contactos con el gobierno federal. La nueva Ley Indígena fue aprobada por el número necesario de congresos locales, aunque las anomalías en el proceso de votación llevaron a más de trescientas comunidades a presentar quejas formales ante la Suprema Corte de la Nación. Sin embargo, el presidente Fox firmó la legislación, la cual entró en vigor en agosto del 2001. Un año después, la Corte declaró que no tenía competencia para anular esta ley y, con ello, se concretó la contrarreforma indígena.

\section{Reforma constitucional y ciudadanía pluriétnica}

Aparte de los procesos de paz, las asambleas constituyentes han sido espacios importantes para negociar la reforma del Estado y permitir la participación de grupos tradicionalmente marginados de la vida política. Es importante recordar que, en 1994, los zapatistas llamaron a la elección de un gobierno de transición y una asamblea constituyente, con la función de crear una nueva Constitución política. Su llamado no avanzó por varias razones, incluidas las divisiones entre los diversos grupos que conformaban la Convención Nacional Democrática (CND), organismo convocado por el EZLN para lograr este fin. Por otra parte, con las reformas electorales y la elevada participación de los votantes en los comicios presidenciales se evitó una crisis política similar a la de 1988. En estas condiciones, los partidos lograron conducir el cambio político 
sin tener que recurrir a una nueva asamblea constituyente. Es necesario subrayar este punto porque, en otros países latinoamericanos, los movimientos indígenas lograron insertar sus demandas políticas en contextos más inestables y, por lo tanto, menos controlados por los partidos y elites tradicionales.

De hecho, en algunos casos, el reconocimiento de los derechos indígenas se convirtió en una necesidad para superar momentos de profunda crisis política. En Colombia y el Ecuador, las crisis de legitimidad en los noventa fueron tan grandes que los grupos de poder no podían asegurar la estabilidad a través de los canales existentes. En ambos casos, la legitimidad había sido erosionada por el clientelismo y la corrupción de los partidos políticos dominantes, la exclusión de otras fuerzas políticas y, sobre todo en el caso colombiano, la participación del Estado en la violación de los derechos humanos y en la violencia política. En estos dos países se celebraron elecciones especiales para conformar asambleas constituyentes, las cuales redactaron nuevas constituciones nacionales (en 1991 en Colombia, y en 1998 en el Ecuador). En ambos procesos, los movimientos indígenas lograron aprovechar su experiencia de lucha y sus relaciones con otros actores importantes para introducir en los debates constitucionales sus propias demandas. Otros factores que les permitieron incidir de esta manera incluyeron el apoyo recibido por parte de un bloque de representantes de partidos de izquierda que simpatizaban con su lucha y la relativa unidad de las diversas corrientes de los movimientos indígenas, en la coyuntura especial que representaba la celebración de una asamblea constituyente (Van Cott, 2001).

¿Cuáles son los cambios logrados en los respectivos textos constitucionales? En Colombia, la Constitución de 1991 protege el carácter inalienable de las tierras comunales (resguardos), reconoce a los pueblos indígenas como sujetos colectivos y les otorga el mismo rango jurídico de que gozan los municipios colombianos. Según la Constitución, los resguardos deben recibir la misma proporción de fondos públicos que los municipios y están reconocidos en su autonomía para gobernarse según sus propias autoridades indígenas (cabildos). Sin embargo, la implementación de estos cambios ha enfrentado varios obstáculos, desde la oposición de los terratenientes hasta las incursiones de las diferentes fuerzas involucradas en la violenta disputa por el territorio en Colombia: los narcotraficantes, la guerrilla, los paramilitares y el ejército (Rathgeber, 2004). Los avances más tangibles se han dado en el reconocimiento del derecho consuetudinario indígena, debido en gran medida al apoyo de la Corte Constitucional de Colombia, la cual fue una creación de la misma Constitución de 1991 (Van Cott, 2000: 110-118).

En el Ecuador, el movimiento indígena logró participar en los debates de la asamblea constituyente en 1998 debido a varios factores. En primer lugar, fueron electos a la asamblea algunos de los representantes del Movimiento de Unidad Plurinacional Pachacutik (MUPP), un partido indígena que había sido formado por una decisión de la CONAIE y otros movimientos sociales para participar en las elecciones de 1996. Dada la gran fragmentación del sistema de partidos en el Ecuador, el MUPP pudo formar una alianza importante con partidos de izquierda y así lograr la ratificación del Convenio 169 de la OIT, además de la inclusión de algunas de sus propias propuestas en la nueva Constitución nacional.

Por ejemplo, el nuevo texto constitucional ecuatoriano reconoce los siguientes puntos: el 
carácter inalienable de las tierras comunales; la existencia de circunscripciones territoriales indígenas y de afroecuatorianos; las prácticas indígenas en la impartición de justicia; el derecho a la educación en lenguas indígenas; la participación en todas las dependencias del gobierno; la gestión de proyectos de desarrollo a partir de los valores y criterios de las culturas indígenas; la inclusión en la toma de decisiones sobre el uso y conservación de los recursos naturales; las prácticas tradicionales de la medicina indígena y los derechos de propiedad intelectual colectivos. Al igual que en Colombia, la implementación de dichas reformas depende de muchos otros factores, pero el hecho de que hayan sido plasmadas en la Constitución permite su defensa y promoción en la construcción de una democracia pluriétnica.

Es importante señalar que la participación del movimiento indígena ecuatoriano no se limitó a este espacio institucional, sino que, en el mismo momento de la asamblea consituyente, organizó una asamblea paralela junto con la Coordinadora de Movimientos Sociales. De esta asamblea paralela surgieron las demandas por una democracia participativa con el fin de superar la brecha entre el modelo dominante de democracia representativa y el ejercicio de la soberanía popular (Andolina, 2003), se logró que algunas de estas demandas fueran incorporadas en la nueva Constitución, como la revocación del mandato, el referéndum por inciativa ciudadana y nuevas medidas para garantizar la rendición de cuentas de los funcionarios públicos y representantes electos. Cabe señalar que estas últimas son las mismas reformas que los zapatistas propusieron en la mesa dos de los diálogos de San Andrés sobre democracia y justicia en julio de 1996, pero, por las razones ya señaladas, no fueron escuchadas por el gobierno. Sin embargo, estas propuestas siguen siendo elementos clave para una eventual reforma democrática en México, o en palabras de los zapatistas, el cumplimiento del principio de mandar obedeciendo (EZLN, 2001).

Alcances y limitaciones de los derechos indígenas

El debate latinoamericano en torno a la ciudadanía étnica y los derechos indígenas ha puesto mayor atención en las limitaciones de las políticas de reconocimiento. Los estudios de caso han demostrado grandes obstáculos sociales, económicos y políticos que enfrentan los pueblos indígenas en sus intentos de ejercer la autonomía, aun en aquellos países como Colombia en los que se han visto más avances en cuanto a la legislación nacional.

Díaz Polanco y Sánchez también se refieren a lo "claroscuro" del debate en torno a los derechos indígenas (2002). Afirman que, por un lado, el marco legal internacional demuestra avances importantes, en el que se rompe con los viejos esquemas asimilacionistas y etnocéntricos de los estados nacionales. Pero, por otro lado, reconocen las limitaciones actuales y potenciales de la nueva normatividad internacional. Mencionan que el Convenio 169 de la OIT sigue siendo el instrumento más avanzado en materia indígena porque incluye un conjunto de derechos a la tierra, el empleo, la salud y la educación. Sin embargo, en el Convenio no se lo relaciona con los derechos políticos de los pueblos indígenas. Los gobiernos latinoamericanos que han ratificado este convenio han podido utilizar un discurso de respeto a las diferencias culturales, sin tener que reconocer el derecho a la autodeterminación política de los pueblos. En el caso de México, esta limitante se refleja también en los Acuerdos de San Andrés (y fue señalada en su momento por los mismos zapatistas), pero se 
nota aún más en la Ley Indígena del 2001, la cual mantiene intacta la subordinación de los pueblos indígenas a las políticas de Estado. Díaz Polanco y Sánchez expresan una gran preocupación, que no se limita a México, en el sentido de que los Estados nacionales pueden aprovechar el discurso multicultural para precisamente evitar la necesidad de implementar reformas estructurales.

Frente a esta situación, el reconocimiento debe de ser ligado a las demandas por la redistibución de la riqueza, asegurando el acceso equitativo a la tierra y los recursos que permitan a los pueblos indígenas ejercer realmente sus derechos como pueblos. El reconocimiento sin redistribución no ofrece ninguna solución a los conflictos sociales, y tiende solamente a ganarle un poco de legitimidad al Estado. No es extraño que las reformas sectoriales (por ejemplo, la privatización de la tierra y el agua) hayan ocurrido al mismo tiempo que se anuncian las nuevas políticas de descentralización y de reconocimiento de derechos indígenas limitados. Es por esa combinación de políticas públicas que el estado neoliberal busca conciliar la globalización económica con la expresión regulada de la diversidad cultural. Hernández, Sierra y $\mathrm{Paz}$ (2004) caracterizan este modelo como un tipo de 'capitalismo multicultural,' el cual describe en gran medida la visión empresarial del gobierno panista de Vicente Fox (2000-2006). Por su parte, Assies demuestra la necesidad de realizar nuevas investigaciones para iluminar más las relaciones entre las nuevas reformas constitucionales y las prácticas concretas en los diferentes países latinoamericanos. Estos argumentos conforman una crítica oportuna al neoliberalismo, entendido éste como una tecnología de poder que produce una ciudadanía regulada por las habilidades comerciales, por encima de la membresía nacional (Ong, 2006).
Sin embargo, existen alternativas al “capitalismo multicultural". Por ejemplo, un amplio número de organizaciones no gubernamentales han participado en debates internacionales para fortalecer el marco jurídico en materia indígena. Tienen esperanzas en cuanto a las posibles transformaciones que podrían derivarse de la aceptación de la Declaracion de Derechos de los Pueblos Indígenas de la ONU. A diferencia del Convenio 169 de la OIT, esta Declaración, que ha sido debatida a partir de 1995, permite la autodeterminacion de los pueblos indígenas en términos más ventajosos. La legislación anterior dejaba que el Estado nacional determinara el alcance de la autonomía indígena $\mathrm{y}$, como hemos visto, el resultado no ha sido favorable para el ejercicio de los derechos colectivos, sobre todo en relación con el uso de los recursos naturales y la tierra. La nueva Declaración pretende superar estas trabas al reconocer el derecho a la autodeterminación de los pueblos.

Después de una década de presiones y negociaciones, el 29 de junio de 2006, el Consejo de Derechos Humanos de la ONU aprobó por voto mayoritario el texto de la Declaración, el cual fue bien recibido por las organizaciones que participan en estos espacios de discusión. Sin embargo, en noviembre del mismo año, la Tercera Comisión de la Asamblea General de la ONU decidió aplazar "el examen y la adopción de medidas" en torno a la Declaración hasta el final del sexagésimo período de sesiones de la Asamblea, en septiembre de 2007. La demora se debe a la oposición de los gobiernos de varios países, sobre todo de los Estados Unidos, Canadá, Rusia, Nueva Zelandia y Australia, los que consideran inoperantes las medidas que permitirían a los pueblos indígenas ejercer 
mayor control sobre los recursos naturales en sus territorios. Está por verse si una mayoría de los Estados miembros de la ONU deciden apoyar la nueva Declaración, pero la prolongación de la consulta deja más oportunidades para que sus opositores traten de modificar los artículos más contenciosos (IWGIA, 2006). Además, existe el reto constante de llevar a cabo cualquier declaración internacional. De hecho, los informes de la ONU siguen lamentando "la brecha de implementación" de los derechos indígenas internacionales por parte de los gobiernos nacionales (Stavenhagen, 2007).

Otro obstáculo que está cobrando cada vez mayor importancia es la criminalización de la protesta social. Esto se debe en parte a las políticas de seguridad que se han puesto en funcionamiento a raíz de los ataques del once de septiembre de 2001 en los Estados Unidos, y a la tendencia de los gobiernos a tomar medidas que dan prioridad a la protección de la infraestructura e intereses de inversionistas por encima de la defensa de los derechos políticos y civiles de las poblaciones afectadas. Por ejemplo, el Consejo Nacional de Inteligencia de los Estados Unidos ha señalado que los movimientos indígenas en América Latina representan un potencial peligro para la estabilidad del mercado y la misma seguridad nacional estadounidense. En igual tono, el exmandatario español José María Aznar publicó un libro en 2006, America Latina: Una agenda de libertad, en el cual considera como terroristas a los movimientos indígenas, equiparándolos con los violentos nacionalismos europeos que promueven la 'limpieza étnica' y la desintegración del Estado (López y Rivas, 2007).

Más allá de la retórica, existen numerosos casos en los que se ha buscado criminalizar las acciones tomadas por diversos pueblos indígenas para defender sus tierras, bosques y recursos naturales. El relator especial sobre la situación de los derechos humanos y libertades fundamentales de los indígenas, Rodolfo Stavehagen, describe en su informe de 2006 la manera en que varios pueblos han sido reprimidos violentamente por haber recurrido a nuevas formas de organización y movilización. Por ejemplo, dicho informe menciona la represión en Atenco y Oaxaca, en 2006, la cual dejó un saldo de por lo menos 20 personas muertas, 350 detenidos y 370 lesionados, además de muchas violaciones a la libertad de expresión, amenazas, violaciones sexuales y torturas cometidas por diversos agentes del Estado y grupos paramilitares, los cuales siguen gozando de la impunidad (Stavenhagen, 2007: 14).

A pesar de estos obstáculos, los pueblos indígenas siguen buscando salidas políticas que llevarán finalmente a su reconocimiento con redistribución. La autonomía sigue siendo una demanda vigente, expresada en varios foros y encuentros, movilizaciones, organizaciones y en la vida cotidiana. Un ejemplo reciente es la tercera Cumbre Continental de Pueblos y Nacionalidades del Abya Yala, realizada en Guatemala, en marzo de 2007, en la cual la articulación entre los derechos indígenas y la ciudadanía pluriétnica se manifiesta en uno de sus objetivos: "Consolidar los procesos impulsados para fortalecer la refundación de los estados-nación y la construcción de los estados plurinacionales y sociedades interculturales mediante las Asambleas Constituyentes con representación directa de los pueblos y nacionalidades indígenas" (citado por López y Rivas, 2007). Es en este contexto de lucha renovada que debemos entender la nueva etapa del movimiento zapatista en México. 


\section{La "segunda" rebelión zapatista: la sexta declaración y la otra campaña}

Después de la Marcha del Color de la Tierra, el EZLN tuvo que reconsiderar los alcances de su lucha por una reforma constitucional. Como ya señalamos, esta lucha ha sido frustrada por los tres poderes del Estado. El ejecutivo ha utilizado la represión y el hostigamiento, junto con el ofrecimiento de reformas parciales con el fin de dejar intactas las bases de un sistema económica y culturalmente desigual. Por su parte, el poder legislativo, con la participación de todos los partidos políticos, modificó la iniciativa de ley de la COCOPA, y dejó en su lugar una legislación que ni siquiera alcanza las normas internacionales en materia de derechos indígenas. Por último, el poder judicial optó por no aceptar las controversias presentadas por más de trescientos municipios en contra de la Ley Indígena.

Ante esta negativa de las instituciones, el EZLN regresó a sus comunidades para, desde ahí, construir una alternativa basada en dos conceptos clave: la autonomía y la solidaridad. Después de la Marcha del Color de la Tierra, en abril de 2001, los zapatistas se dedicaban más a la consolidacion de proyectos locales de autonomía local. Sin embargo, el anuncio en junio de 2005 de la Sexta Declaración de la Selva Lacandona representó un nuevo intento de articularse con distintos movimientos sociales en México y en el mundo. La diferencia más notable de esta declaración fue su independencia contundente frente a todos los partidos políticos y las instituciones oficiales. Si el EZLN ya había expresado su rechazo a las formas tradicionales de hacer política en México, la Sexta reafirmó su postura en el contexto coyuntural de las elecciones presidenciales programadas para el 2 de julio de 2006.

Ya era evidente que, en palabras del Subcomandante Marcos, los zapatistas "no esperaban nada de arriba”. Si la primera Declaración de la Selva Lacandona representó una rebelión contra el PRI, Salinas y el neoliberalismo, la Sexta se dirigió en contra de todos los partidos, todos los candidatos presidenciales y el capitalismo. En los años que van de la instalación de la primera mesa de diálogo en San Andrés hasta la Marcha del Color de la Tierra (octubre de 1995 a abril de 2001), fue la lucha por la ciudadanía pluriétnica la que marcó casi todas las iniciativas del zapatismo. Entre ellas se destacaron la firma de los Acuerdos sobre Derechos y Cultura Indígenas (febrero de 1996); la Marcha de las 1,111 bases de apoyo a la Ciudad de México (septiembre de 1997); la Quinta Declaración de la Selva Lacandona (julio de 1998); la Consulta Nacional e Internacional sobre los Derechos y la Cultura Indígenas y por el Fin de la Guerra de Exterminio (marzo de 1999); y la misma Marcha del Color de la Tierra. Es decir, una solución política al conflicto en Chiapas se imaginaba dentro del marco de la ciudadanía pluriétnica, tal y como se ha ido dando en otros países latinoamericanos. La anulación de esta salida explica en gran parte las características de la Sexta Declaración, la cual llevó a la formación de la "Otra Campaña” en el verano de 2005. Con todo, no es una exageración decir que la Sexta Declaración y la Otra Campaña representan una "segunda rebelión zapatista," la cual busca construir alternativas desde los grupos más marginados de la sociedad.

Durante el 2006, este movimiento intentó crear una nueva red de grupos e individuos solidarios, unificados por su desencanto con el sistema 
existente y agraviados por la violación o negación de sus derechos cívicos, políticos y sociales, es decir, su ciudadanía. Ejemplos notables lo son los simpatizantes de los movimientos sociales en San Salvador Atenco y en Oaxaca, quienes sufrieron muchas muertes, desapariciones forzadas y agresiones sexuales a manos de policías y paramilitares que actúan con impunidad. A pesar de este clima político autoritario, la Otra Campaña participó durante 2006 en cientos de reuniones con adherentes a lo largo del país, tomó la iniciativa de organizar una Campaña Mundial por la Defensa de las Tierras y los Territorios Indígenas y Campesinos, Autonómos, en Chiapas, México y el Mundo, y promovió un Encuentro de Pueblos Indígenas de América, en octubre de 2007.

Al iniciar un nuevo sexenio, México enfrenta una grave crisis política. Los fraudes cometidos en los comicios presidenciales, en 2006, aumentaron la desconfianza popular hacia el sistema electoral y el nuevo poder ejecutivo. En tales condiciones, como señala Durand Ponte (2004: 273), el mayor peligro es la consolidación del "círculo del autoritarismo". Este círculo se refiere a la relación perversa entre, por un lado, la mala evaluación del desempeño del gobierno y de la economía del país $y$, por el otro, la pérdida de eficacia ciudadana, lo cual lleva al desencanto respecto a la transición democrática y el regreso de líderes fuertes y el autoritarismo, tanto en las instituciones como en la cultura política. El zapatismo busca fortalecer la resistencia ante este escenario autoritario, $y$ demuestra una necesidad de democratizar la vida social más allá de las vías institucionales existentes. En el camino, la ciudadanía empieza a reflejar una experiencia de solidaridad ante agravios comunes más que seguir siendo una abstraccion jurídica o un concepto teórico.

\section{Notas}

${ }^{1}$ Quisiera agradecer a María Harvey por su ayuda en la corrección de estilo de este artículo, a Inés Castro Apreza por haberme invitado a colaborar en este número de la revista LiminaR y a la persona anómina por su dictamen de una primera versión del texto, por sus comentarios y sugerencias que me ayudaron a revisar el trabajo final.

2 Mexico tiene la población indígena más grande entre todos los países latinoamericanos. Se conforma de 56 grupos etnolinguísticos, con una población estimada en por lo menos diez millones de personas (equivalente al $11 \%$ de la población nacional). Los indígenas conforman una mayoría numérica en dos países: Guatemala (con 5.8 millones, o el $59 \%$ de la población) y Bolivia (4.1 millones, el $65 \%$ ). El Perú y el Ecuador también cuentan con poblaciones indígenas grandes (8.8 millones y 2.1 millones, respectivamente), mientras en Colombia y Brasil la población indígena es relativamente pequeña (620 mil y 254 mil respectivamente). Datos de Minority Rights Group (1997).

\section{Bibliografía}

Andolina, Roberto, 2003, “The sovereign and its shadow : constituent assembly and indigenous movement in Ecuador", Journal of Latin American Studies, vol. 35, núm. 4, pp. 721-750.

Assies, Willem, 1999, "Introducción”, en Willem Assies, Gemma van der Haar y André Hoekema, eds, El reto de la diversidad, El Colegio de Michoacán, Zamora, México.

De la Peña, Guillermo, 1999, "Notas preliminares sobre ciudadanía étnica (el caso de México)”, en Alberto J. Olivera (coord.), La sociedad civil: de la teoría a la realidad, El Colegio de México, México.

Díaz-Polanco, Héctor, 2004, El Canon Snorri: diversidad Cultural y Tolerancia, Universidad de la Ciudad de México, México.

Díaz-Polanco, Héctor y Consuelo Sánchez, 2002, México Diverso: el debate por la autonomía, Siglo XXI Editores, México.

Durand Ponte, Víctor Manuel, 2004, Ciudadanía y Cultura Politica: México, 1993-2001, Siglo XXI Editores, México. 
EZLN (Ejército Zapatista de Liberación Nacional), 2001, Democracia Sustantiva, Democracia Social (segunda reimpresión). México D.F., Berbera Editores, 2001

Fraser, Nancy and Linda Gordon, 1994, "Civil Citizenship against Social Citizenship?”, en Bart Van Steenbergen (coord.), The Condition of Citizenship, Sage Publications, Londres, pp.90-107.

González Casanova, Pablo y Marcos Roitman (coords.), 1996, Democracia y Estado Multiétnico en América Latina, UNAM y La Jornada Ediciones, México.

Harvey, Neil, 2000, La Rebelión de Chiapas, Ediciones Era, México.

Harvey, Neil, 2004, "Disputando el desarrollo: derechos indígenas y el Plan Puebla Panamá en Chiapas”, en Rosalva Aída Hernández Castillo, Teresa Sierra y Fernanda Paz (coords.), El Estado y los Indígenas en Tiempos del PAN : neoindigenismo, legalidad e identidad, CIESAS y Editorial Porrúa, México, pp. 115-136.

Hernández Navarro, Luis y Ramón Vera Herrera, 1998, Acuerdos de San Andrés, Ediciones Era, México.

Hernández Castillo, Rosalva Aída, Teresa Sierra y Fernanda Paz (coords.), 2004, El Estado y los Indígenas en Tiempos del PAN: neoindigenismo, legalidad e identidad, CIESAS y Editorial Porrúa, México.

Higgins, Nicholas, 2001, "Mexico's stalled peace process: prospects and challenges”, International Affairs, vol. 77, núm. 4, 2001, pp.885-903.

IWGIA (Internacional Working Group for Indigenous Affairs), 2006, "Articles, statements and press releases on the UN Declaration on the Rights of Indigenous Peoples", Sitio web: http://www. iwgia.org/sw18043.asp, consultado el 3 de mayo del 2007.

Kymlicka, Will, 2002, Contemporary Political Philosophy: an introduction, Oxford University Press, Oxford.

López Bárcenas, Francisco, 2002, Autonomía y Derechos Indígenas en México, Conaculta, México.

López y Rivas, Gilberto, 2007, "Pueblos Indígenas: entre agresiones y resistencias", La Jornada, 20 de abril.

Marshall, T.H., [1949] 1998, "Citizenship and Social Class" en Gershon Shafer (coord.), The Citizenship
Debates: a reader, University of Minnesota Press, Minneapolis, pp. 93-111.

Minority Rights Group, 1997, World Directory of Minorities. Minority Rights Group International, Londres.

Ong, Aiwha, 2006, Neoliberalism as Exception: mutations in citizenship and sovereignty, Duke University Press, Durham.

Rathgeber, Theodor, 2004, "Indigenous struggles in Colombia: historical changes and perspectives", en Nancy Grey Postero y León Zámosc, eds. The Struggle for Indigenous Rights in Latin America, Sussex Academic Press, Reino Unido, pp.105-130.

Revista Memoria, 2003, "Caracoles Zapatistas: Autonomía y Buen Gobierno”, Revista Memoria, núm. 176, octubre, México, pp.5-30.

Stavenhagen, Rodolfo, 1996, "Indigenous Rights: Some Conceptual Problems", en Elizabeth Jelin y Eric Hershberg (coords.), Constructing Democracy: Human Rights, Citizenship and Society in Latin America, Westview Press, Boulder, pp.141-160.

Stavenhagen, Rodolfo, 2007, Informe del Relator Especial sobre la situación de los derechos humanos y libertades fundamentales de los indígenas, Consejo de Derechos Humanos de la Organización de las Naciones Unidas, Cuarto Periodo de Sesiones A/HRC/4/32, 27 de febrero.

Van Cott, Donna Lee, 2000, The Friendly Liquidation of the Past: the Politics of Diversity in Latin America, University of Pittsburgh Press, Pittsburgh.

Van Cott, Donna Lee, 2001, "Explaining ethnic autonomy regimes in Latin America", Studies in Comparative International Development, vol. 35, núm. 4, pp.30-58.

Yashar, Deborah, 1999, "Democracy, Indigenous Movements and the Post-Liberal Challenge in Latin America”, World Politics, vol. 52, núm. 1, pp. 76-104

Young, Iris Marion, 1998, "Polity and Group Difference: a critique of the ideal of universal citizenship", en Gershon Shafer (coord.), The Citizenship Debates: a reader, University of Minnesota Press, Minneapolis, pp. 263-290. 